\title{
"MULHERES NAS CIÊNCIAS EXATAS E TECNOLOGIAS": PERCEPÇÕES DE CONCLUINTES DO ENSINO MÉDIO DE DISTINTOS AMBIENTES SOCIOEDUCACIONAIS
}

"Women in Exact and Technological Sciences": perceptions of concluints in high school of distinct socio-educational environments

"Mujeres en las Ciencias y Tecnologías Exactas": percepciones de las concluintas del bachillerato de diferentes entornos socioeducativos

\section{Ulisses Franklin Carvalho da Cunha ${ }^{1}$, Magale Karine Diel Rambo ${ }^{2}$, Cynthia Mara Miranda $^{3}$}

${ }^{1}$ Bacharel em Psicologia. Mestre em Ciências do Ambiente. Técnico de Nível Superior da Universidade Estadual do Tocantins - Unitins.

${ }^{2}$ Doutorado em Química pela Universidade Estadual de Campinas. Professora do Curso de Engenharia Ambiental e do Programa de Pós-Graduação em Ciências do Ambiente-PPGCIAMB da Universidade Federal do Tocantins - UFT.

3 Doutorado em Ciências Sociais pela Universidade de Brasília. Atualmente é professora adjunta IV da Universidade Federal do Tocantins - UFT, atuando no curso de Jornalismo e no Programa de Pós-Graduação em Comunicação e Sociedade.

Artigo recebido em 28/10/2020 aprovado em 25/10/2021 publicado em 26/10/2021.

\section{RESUMO}

Este estudo propôs-se a refletir acerca da presença das mulheres nas áreas de Ciências Exatas e Tecnologias, na perspectiva das narrativas de alunas do $3^{\circ}$ ano do Ensino Médio, de duas escolas localizadas em distintos ambientes socioeducacionais de uma capital brasileira: uma, sendo pública e em região de vulnerabilidades sociais, e a outra, particular da área central da cidade. Este estudo foi realizado utilizando-se como metodologia de obtenção dos dados o grupo focal, que nos permitiu ter acesso ao imaginário e às opiniões destas adolescentes. As discussões levantadas nos grupos focais foram gravadas, transcritas e submetidas à análise de conteúdo. Os resultados foram discutidos especialmente à luz dos estudos de gênero. As análises realizadas no desenvolvimento do estudo apontam que as adolescentes de ambas as escolas possuem percepções convergentes em diversos pontos que evidenciam a existência de estereótipos de gênero na ciência.

Palavras-chaves: Estereótipos de Gênero. Ciências Exatas e Tecnologias. Engenharias.

\section{ABSTRACT}

This study aimed to reflect on the presence of women in the exact sciences and technologies areas, from the perspective of the narratives of 3rd year high school students, from two schools located in different socio-educational environments of a brazilian capital: one, being public and in a region of social vulnerability, and the other, particularly in the downtown area. This study was conducted using the focal group as a methodology for obtaining data, which allowed us to access the imaginary and opinions of these adolescents. The discussions raised in the focus groups were recorded, transcribed and subjected to content analysis. The results were discussed especially in the light of gender studies. The analyzes carried out in the development of the study indicate that the adolescents from both schools have convergent perceptions in several points that evidence the existence of gender stereotypes in science.

Keywords: Gender Stereotypes. Exact Sciences and Technologies. Engineering.

\section{RESUMEN}

Este estudio tuvo como objetivo reflexionar sobre la presencia de mujeres en las áreas de Ciencias Exactas y Tecnologías, en la perspectiva de las narrativas de egresados de secundaria, de dos escuelas ubicadas en diferentes entornos socioeducativos de una capital brasileña: una, ser pública y en región de vulnerabilidades sociales, y la otra, particularmente la zona central de la ciudad. Este estudio se realizó utilizando el grupo focal como metodología para la obtención de datos, lo que nos permitió tener acceso al imaginario y opiniones de estos adolescentes. Las 
discusiones planteadas en los grupos focales fueron grabadas, transcritas y sometidas a análisis de contenido. Los resultados se discutieron especialmente a la luz de los estudios de género. Los análisis realizados en el desarrollo del estudio muestran que los adolescentes de ambas escuelas tienen percepciones convergentes en varios puntos que evidencian la existencia de estereotipos de género en la ciencia.

Descriptores: Estereotipos de género. Ciencias y Tecnologías Exactas. Ingenieria.

\section{INTRODUÇÃO}

Embora a bem pouco tempo as mulheres tenham conquistado alguns direitos, na vida profissional e em alguns segmentos específicos de carreira e atuação, ainda não houve uma equiparação em relação aos homens, estando (in)visíveis tais discrepâncias e desigualdades; uma vez, por exemplo, que os salários das mulheres, no desempenho das mesmas funções, segundo dados divulgados pelo Instituto Brasileiro de Geografia e Estatística (IBGE, 2019), em uma pesquisa ${ }^{1}$ que analisa as condições de vida das brasileiras, em diferentes ocupações, ainda é inferior aos dos homens. Além dessa disparidade, nota-se que a divisão sexual entre as profissões ainda persiste.

Comprometida com a responsabilidade de promover a igualdade de gênero em Ciência, Tecnologia, Engenharia e Matemática (áreas historicamente dominadas pela presença masculina), a empresa europeia Elsevier - maior editora de literatura científica do mundo - lançou em 08 de Março de 2017 um importante relatório - Gender in the Global Research Landscape - que cobriu 20 anos, 12 regiões geográficas e 27 áreas temáticas, fornecendo informações e orientações poderosas sobre pesquisa de gênero e políticas de igualdade de gênero para governos, financiadores e instituições em todo o mundo (ELSEVIER, 2017).

De modo geral os dados apresentados no relatório apontaram um progresso significativo em direção ao equilíbrio de gênero na pesquisa em todas as 12 áreas do globo investigadas (Estados Unidos, União Europeia, Reino Unido, Canadá, Austrália, França, Brasil, Japão, Dinamarca, Portugal, México e Chile), todavia, esse fenômeno não aconteceu de forma homogênea em todos eles, tampouco no que se refere a áreas mais específicas dentro das Ciências Exatas e suas Tecnologias, apontando, por exemplo, que as áreas de Saúde e Ciências da Vida são as que apresentam a maior representação de mulheres (ELSEVIER, 2017).

Estas informações, de modo sucinto, revelam um apanhado superficial de algumas questões que permeiam o universo das ciências e tecnologias na interface com as questões de gênero. Se o acesso das mulheres à educação superior é algo que vem sendo superado gradativamente, e não mais se constituindo um problema, questionam-se então, quais são os estereótipos e as discriminações ainda persistentes que contribuem para que as mulheres ainda sejam tão poucas nas áreas das ciências exatas e tecnologias.

Neste sentido, o presente estudo buscou debruçar-se acerca desta temática, tendo como objetivo geral responder à seguinte pergunta: o que alunas concluintes do $3^{\circ}$ ano do Ensino Médio, de escolas localizadas em distintos ambientes socioeducacionais, pensam a respeito da inserção e atuação das mulheres nas áreas de Ciências Exatas e Tecnologias?

1 Estudo disponível em: https://biblioteca.ibge.gov.br/visualizacao/livros/liv10167 8.pdf 


\section{Sexo biológico versus gênero e suas implicações para o sujeito mulher}

Quando referimo-nos à presença das mulheres em áreas dominadas por homens - caso das ciências exatas e tecnologias - o conceito de sexo biológico, gênero e os papéis sociais que a ele se vinculam oferecem uma perspectiva de análise para compreensão da desigualdade entre os gêneros nas profissões. Deste modo, estabelecer um marco teórico acerca da epistemologia destes termos faz-se importante para a compreensão do fenômeno da presença e atuação das mulheres nas ciências exatas e tecnologias.

$\mathrm{Na}$ concepção de Oka e Laurenti (2018) definir os conceitos de 'sexo' e 'gênero' é importante porque revelam, em parte, a oposição fundante entre natureza e cultura e a dicotomia entre ciências humanas e biociências, tendo em vista a multiplicidade de usos destes termos. Para estes autores "estes conceitos emergem como termos que se referem a dois campos opostos em disputa: de um lado, as características estritamente bioquímicas e fisiológicas estudadas pelas biociências e, de outro, a dimensão subjetiva e cultural do que é ser mulher ou ser homem" (OKA e LAURENTI, 2018, p. 240).

As discussões que permeiam o universo do sexo biológico e da categoria gênero, especialmente nos estudos pós década de 70 e 80, a partir da ascensão do movimento feminista, trazem consigo o postulado de que o sexo é uma base natural, biológica e invariável sobre a qual as culturas constroem, por meio da socialização, diferentes concepções do que seja um homem ou uma mulher (CARVALHO, 2011); a categoria gênero, por sua vez, desconstruída pela crítica feminista, evidencia uma nova dialética de significado e atribuições, pois, desconstrói a suposta base biológica dos comportamentos masculinos e femininos afirmando que o gênero resulta das construções sociais e culturais (BANDEIRA, 2008; NICHOLSON, 2000). Gênero, portanto, refere-se à dimensão social da sexualidade humana.

Scott $^{2}$ (1989) traz a discussão acerca do gênero para um novo patamar de estudos, no qual o interesse de suas reflexões são as formas como se constroem significados culturais para as diferenças de gênero, dando sentido para elas e, consequentemente, posicionando-as dentro de relações hierárquicas; como ela mesma aponta, o gênero é tratado em sua trajetória de estudos num sentido mais literal, como uma maneira de referir-se à organização social da relação entre os sexos (SCOTT, 1989).

Nas palavras de Carvalho (2011) a utilidade analítica de gênero colocada por Scott (1989) encontra-se na possibilidade de aprofundamento dos sentidos construídos sobre os gêneros masculino e feminino, transformando 'homens' e 'mulheres' em perguntas, e não em categorias fixas, dadas de antemão e sem a reflexão necessária; logo para a autora o gênero se exerce através da atribuição cultural feita a um e a outro sexo, estabelecendo padrões e expectativas para homens e mulheres.

Nicholson (2000) ao ponderar acerca das relações existentes entre a biologia (sexo biológico) e a socialização (gênero) traz ao debate o termo 'portacasaco de identidades': o corpo é visto como um tipo de cabide de pé no qual são jogados diferentes artefatos culturais, especificamente os relativos à personalidade e comportamento. Ademais, a autora ao fazer tal associação entre as noções de corpo, personalidade e comportamento, rotula essas noções de fundacionalismo biológico, referindo-se às diferenças e semelhanças em relação ao determinismo biológico, ou seja, a atribuição sistemática das

feminista norte-americana. Um dos principais nomes no estudo de gênero para as Ciências Sociais.

\footnotetext{
${ }^{2}$ Joan Scott, professora de Ciências Sociais no Instituto de Estudos Avançados em Princeton, historiadora e militante
} 
diferenças encontradas entre mulheres e homens a fatores biológicos.

Relevante pontuar que embora para os estudos posteriores à crítica feminista 'gênero' e ‘sexo' sejam usualmente utilizados em oposição: o primeiro se referindo ao que é construído socialmente e o segundo ao que é dado biologicamente, Nicholson (2000) pontua que os termos não devam ser utilizados de forma oposta, logo a concepção biológica de sexo serve de base sobre a qual os significados culturais (gênero) foram atribuídos e construídos historicamente.

Culturalmente existe uma prescrição do que é ser homem e do que é ser mulher, bem como as atribuições que cada um deles deve desenvolver ao longo do ciclo vital. Estas qualidades e características que a sociedade atribui para homens e mulheres, ou ainda o conjunto de crenças acerca dos atributos pessoais adequados a homens e mulheres, constituem os chamados estereótipos de gênero (D'AMORIM, 1997; 1985) e são eles que impulsionam as pessoas a assumirem determinados papéis, tarefas e funções na sociedade.

Dadas essas considerações, pondera-se que o conceito de gênero, enquanto ferramenta teórica, para discussão e análise dos fenômenos sociais, têm possibilitado uma ampla crítica cultural da dominação masculina e da subordinação e opressão feminina. Importante compreender que as noções de sexo biológico e gênero estão imbricados num universo maior que são as relações hierárquicas de poder simbolicamente e culturalmente associadas a elas.

A compreensão e análise das construções sociais atribuídas a elas estão na base do processo de invisibilização a qual foram submetidas as mulheres ao longo da história e contribuem até os dias atuais para um processo de invisibilidade e deslocamento delas para lugares de menor importância e prestígio (CARVALHO, 2004).

\section{Invisibilidades da mulher na história}

Apesar da contemporânea e proclamada igualdade entre mulheres e homens, garantida, inclusive na Constituição Cidadã (BRASIL, 1988), o que se constata é que ainda vivemos uma longa tradição machista; os espaços delegados às mulheres ao longo da história, inclusive nos dias atuais, mesmo com toda a luta do movimento feminista, ainda são pontuados por exclusão, desigualdades e invisibilidades.

Bandeira (2008) afirma que as mulheres, enquanto sujeitos individuais e coletivos, compartilharam ao longo da história das mesmas exclusões e incertezas relativas a outros grupos sociais, tais como determinados grupos étnico-raciais, especialmente nos caminhos da construção científica.

Shumaher (2004) assinala que não é difícil compreender a difusão da cultura machista se levarmos em consideração o modo como as mulheres foram tratadas ao longo da história: acreditando-se que elas seriam inferiores intelectualmente aos homens, e que, portanto, seria inútil oferecer qualquer tipo de educação. Para a autora as desigualdades de gênero são construções seculares e atuantes desde a mais tenra idade de meninas e meninos;

Segundo pontua Matos (2002) a presença das mulheres nos escritos acadêmicos, se fizeram presentes somente após a Segunda Guerra Mundial. Esta presença vem crescendo em função de um conjunto de fatores que tem dado visibilidade às mulheres, mediante suas conquistas por novos espaços de vivência e atuação. Dentre estes espaços conquistados merece destaque o espaço do mercado de trabalho formal, inclusive nas universidades.

Dentre os fatores que contribuíram para a visibilidade e conquista dos direitos pelas mulheres, esteve a expansão da luta das próprias mulheres pela igualdade de direitos, pela liberdade, pela educação feminina e pelo direito ao voto. Reivindicações estas 
derivadas da afirmação dos movimentos feministas e favorecidas pelas profundas transformações sociais, econômicas e políticas advindas pelo pós-guerra (MATOS, 2002).

Neste contexto, Olinto (2011) aponta que diante dessas diferenças de atribuições a qual cada gênero está submetido, as mulheres deparam-se com dois tipos de mecanismos que operam como barreiras que limitam suas chances de vida e funcionam como mecanismos de exclusão: a segregação horizontal e a segregação vertical.

A segregação horizontal, diz respeito à separação para determinadas atividades baseada no gênero do indivíduo, ou seja, através deste mecanismo a sociedade dita o que é trabalho para homem e o que é trabalho para mulher, e assim as mulheres são levadas a fazer escolhas e seguir caminhos notadamente diferentes daqueles escolhidos ou seguidos pelo gênero oposto e vice-versa (OLINTO, 2011). Este conceito encontra amparo nos estereótipos de gênero discutidos anteriormente, pois conforme pontuado por Nicholson (2000) argumentos relativos a explicações biológicas para personalidade e comportamento generalizam equivocadamente aspectos específicos da personalidade e do próprio comportamento para todas as sociedades humanas, influenciando assim rumos e destinos assumidos pelos sujeitos humanos.

A segregação vertical é um mecanismo social talvez ainda mais sutil, que tende a fazer com que as mulheres se mantenham em posições mais subordinadas ou, que não progridam nas suas escolhas profissionais. Este mecanismo de segregação está diretamente vinculado com a desvalorização das profissões femininas, logo, se as mulheres são

3 Uma vez que as participantes do estudo expuseram questões de ordem pessoal, num ambiente de compartilhamento coletivo de informações, e por tratar-se de assuntos que envolveram suas subjetividades, a pesquisa foi submetida e aprovada pelo Comitê de Ética da Universidade Federal do Tocantins- UFT, parecer de desvalorizadas socialmente, suas profissões também são (Olinto, 2011).

Tanto a segregação vertical quanto a horizontal sugerem uma genuína diferença de características e habilidades entre os dois sexos, o que explicaria a exclusão das mulheres de algumas áreas de atuação e segmentos de trabalho e a dificuldade em atingir posições de destaque na hierarquia ocupacional, delegando-se deste modo, as mulheres para lugares de menor valor social e de menor prestígio.

Ao que tudo indica as normas prescritivas da sociedade têm influenciado as escolhas profissionais dos indivíduos e estabelecendo uma divisão sexual do trabalho pautado nas categorias de gênero, ou seja, é como se existissem carreiras de atuação específicas para homens e carreiras específicas para mulheres.

\section{MATERIAIS E MÉTODOS}

A metodologia utilizada para o desenvolvimento da pesquisa foi o grupo focal (BARBOUR, 2009). O público alvo foi dois grupos de estudantes mulheres concluintes do $3^{\circ}$ Ano do Ensino Médio de duas escolas localizadas em distintos ambientes socioeducacionais: uma, sendo pública e em região de vulnerabilidades sociais, e a outra, particular da área central da cidade. Tal escolha, para verificar se as percepções dessas jovens mulheres ${ }^{3}$ apresentavam discrepâncias significativas, de acordo com o lugar de fala e a condição social e econômica dessas jovens mulheres, justificou-se baseada nas questões distintas que permeiam o lugar de existência e de socialização: o centro e a periferia, o sistema educacional público e o sistema educacional privado.

número 3.365.868 e Certificado de Apresentação para Apreciação Ética - CAAE: de número 11358919.2.0000.5519. 
A opção pela técnica do grupo focal, em relação a outras técnicas de captação de informações se deu em função de proporcionar ao pesquisador melhor entendimento e captação das perspectivas subjetivas das participantes, permitindo trazer à tona respostas mais completas e possibilitando também verificar a lógica ou as representações sociais que conduzem às respostas das participantes do grupo.

Em ambas as escolas - pública e privada foram realizados dois encontros com cada um dos grupos focais: na escola pública participaram do grupo focal um total de 11 meninas e na escola privada um total de 10 meninas. As discussões levantadas nos grupos focais foram gravadas, transcritas e submetidas à análise de conteúdo (BARDIN, 2011); para a análise e discussões dos dados coletados, deu-se ênfase, em especial, aos pontos de concordância surgidos dentro de cada grupo focal e entre os dois grupos focais. Categorias de análise serviram de base para as demais interpretações e discussões a partir das narrativas trazidas pelas participantes. Os dados coletados via discussão nos dois grupos focais foram abordados de modo analítico-reflexivo e discutidos em paralelo aos estudos de gênero.

\section{RESULTADOS E DISCUSSÃO}

No primeiro encontro em ambas as escolas a discussão se deu em torno das questões que indagavam acerca de suas pretensões de carreira e escolha profissional, bem como das aptidões e habilidades que meninos e meninas apresentam para determinadas áreas e profissões, com foco nas matérias das áreas de exatas e tecnologias estudadas na educação básica: matemática, física e química. No segundo encontro o pesquisador retomou brevemente os pontos principais contemplados por elas no encontro anterior e prosseguiu com a discussão problematizando a questão chave: porque as mulheres ingressam menos nas áreas das Ciências Exatas e Tecnologias?
Nos momentos iniciais de ambos os grupos focais, questionou-se a elas posterior a afirmarem que gostariam de continuar os estudos e ingressar num curso superior: "que curso vocês pretendem ingressar após finalizarem o ensino médio?". No grupo focal 1 (escola pública) três delas afirmaram querer estudar medicina, duas delas direito, uma ciências biológicas, uma zootecnia, uma psicologia, uma ciências contábeis, uma administração e uma outra nutrição. No grupo focal 2 (escola privada) obteve-se como resposta duas delas desejando o curso de medicina, duas o curso de psicologia, duas afirmaram não saber ainda o que pretendem cursar, uma delas administração, uma o curso de direito, outra participante o curso de nutrição e outra o curso de arquitetura e urbanismo.

Nota-se em primeira instância, que em nenhum dos grupos focais obteve-se como resposta qualquer curso ligado às áreas de exatas ou tecnologias, predominando em ambos os grupos respostas associadas aos cursos das áreas de sociais aplicadas e saúde o que corrobora com os estudos mencionados anteriormente que apontam o baixo interesse pelas mulheres por estas áreas de estudo e atuação (INCT-CPCT, 2019; LETA, 2003).

Prosseguindo com as discussões em grupo, surgiram então as narrativas com maiores exposições e prolongamento das ideias; embora tenha havido uma série de pontos convergentes nas narrativas das estudantes dentro e entre os grupos focais em ambas as escolas, surgiram também pontos divergentes e percepções bastante individuais, conforme prescreve a metodologia. Os pontos convergentes, que em suma foram as respostas obtidas pela interação das participantes no grupo focal, que em maior ou menor grau mantiveram um olhar semelhante em relação ao tópico apresentado pelo pesquisador, são descritos nas Tabelas 1 e 2, das questões consensuais do grupo focal 1 (escola pública) e do grupo focal 2 (escola privada). 
Tabela 1: Tabela das Questões Consensuais no Grupo Focal 1 - Escola Pública.

Vocês poderiam citar exemplo de profissão que Todas concordaram com engenharia e mecânica. quando a gente fala vocês lembram imediatamente de um homem atuando?

\begin{abstract}
Vocês acreditam que essas profissões (engenharia e mecânica) são mais indicadas e melhor desempenhadas por homens?
\end{abstract}

Para vocês o que é uma cientista?

Vocês conhecem ou lembram-se do nome de alguma cientista brasileira ou cientista mulher de importante atuação?

Vocês concordam que meninos e meninas têm a mesma capacidade para aprender matemática, química, física, matérias que são de áreas exatas?

As mulheres podem apresentar o mesmo desempenho, fazer bem feito quando elas estão trabalhando nas áreas de exatas, como, por exemplo, nas engenharias?

Vocês acreditam que mulheres conseguem concluir com sucesso cursos destas áreas?

Vocês acreditam que tem poucas mulheres nas áreas de exatas e tecnologias porque todos dizem para elas que aquilo não é para mulheres?

Quais profissões vocês acreditam que são mais indicadas para mulheres?

Vocês acreditam que o fato de ter poucas mulheres nas áreas de exatas e tecnologias inibe que outras mulheres escolham por estas áreas?

Todas afirmaram que não e acrescentaram que homens e mulheres teriam a mesma capacidade para desempenhar ambas as profissões.

Alguém que faz pesquisa e descobre novas coisas.

Não lembravam ou não sabiam

Todas concordaram que sim.

Todas concordaram que sim e acrescentaram que depende do quanto ela estudou e se dedicou para estar ali.

\section{Todas concordaram que sim.}

Todas concordaram que existem preconceitos contra as mulheres nestas áreas e que a própria formação da menina (formação cultural recebida dentro de casa e na própria sociedade) a distancia da escolha por estas profissões.

"Professora e enfermagem". As demais participantes concordaram com estas duas profissões.

Todas concordaram e afirmaram que ela poderia sentir-se intimidada e incluíram que o medo da exclusão posterior no mercado de trabalho poderia influir para que ela desistisse.

Nenhuma delas conhecia.

Vocês conhecem alguma mulher que esteja
trabalhando numa área dominada por homens como a engenharia civil, por exemplo.

Se vocês conhecessem várias mulheres que trabalham nestas áreas vocês se sentiriam mais seguras para estudar e atuar nestas áreas?

Fonte: Elaborado pelo autor a partir dos dados da pesquisa (2019).

Reitera-se que as tabelas consensuais do grupo focal 1 e 2 apresentam algumas perguntas distintas entre si devido à não concordância total das respostas obtidas, apresentando-se, portanto, em ambas as tabelas apenas as perguntas e respostas em que houve unanimidade dentre as participantes; logo por tratar-se de um momento de livre exposição de ideias e pensamentos, proporcionados pela discussão em grupo, surgiram ao longo dos encontros e em ambos os 
grupos focais divergências e exposição de opiniões

bastante individuais de cada uma.

Tabela 2: Tabela das Questões Consensuais no Grupo Focal 2 - Escola Privada.

Vocês poderiam citar exemplo de profissão que quando a gente fala vocês lembram imediatamente de um homem atuando?

Por exemplo, há mulheres que são engenheiras civis, vocês acreditam que elas desempenham o trabalho com menos eficiência que o homem, simplesmente por ser mulher?

Quais profissões vocês acreditam que são mais indicadas para mulheres?
Todas concordaram com as engenharias, mas acrescentou-se que isso ocorre devido ao fato de serem profissões que exigem maior esforço físico ou que não chamam a atenção do público feminino.

Todos afirmaram que não e incluíram dedicação e esforço como quesitos para o mesmo desempenho.

"Professora de criancinha; maternal e enfermagem, pela questão do cuidado e da delicadeza; médica ginecologista"; as demais concordaram com estas sugestões dadas pelas primeiras respondentes.

\section{Para vocês o que é uma cientista?} alguma cientista brasileira ou cientista mulher de importante atuação?

Vocês concordam que meninos e meninas têm a mesma facilidade para aprender matemática, química, física, matérias que são de áreas exatas?

O que acontece então, se meninos e meninas têm a mesma facilidade com as exatas, para que tenha poucas mulheres nessas áreas?

\section{Vocês acreditam que mulheres conseguem concluir com sucesso cursos destas áreas? \\ Vocês acreditam que a falta de mulheres nestes cursos prejudicam a sociedade de alguma forma ou as próprias mulheres? \\ O que contribui para que tenha poucas mulheres nas áreas de exatas e mais na área da saúde? \\ Depois do que conversamos ao longo destes dois encontros vocês acreditam que mesmo assim ainda existe essa questão de profissão para homem e profissão para mulher?}

"Uma pessoa que pega um assunto e busca um conhecimento mais aprofundado". As demais concordaram com esta definição dada pela primeira respondente.

Não lembravam ou não sabiam

Todas concordaram que se trata de uma questão de identificação e dedicação, indiferente do gênero.

Todas concordaram tratar-se de uma questão imposta pela sociedade e que naturalmente homens e mulheres são levados a fazer coisas que já estão colocadas pelo social (família e normas da sociedade).

Todas concordaram que sim.

Todas concordaram que sim pelo fato de aumentar o próprio preconceito contra as mulheres.

Todas concordaram tratar-se de questões sociais de que a mulher tem que ser 'cuidadosa, maternal e delicada'.

Todas concordaram que não.

Fonte: Elaborado pelo autor a partir dos dados da pesquisa (2019).

Nota-se, deste modo, que houve vários pontos de vista

e percepções comumente compartilhados e confirmados pelo conjunto de alunas da escola pública; destaca-se, em nível de compreensão e 
proximidade com os objetivos deste estudo a associação imediata que todas elas fizeram das áreas de engenharia e mecânica como profissões masculinas e das profissões de professora e enfermeira como sendo profissões femininas. Embora tenham feito essas associações, todas acreditam no potencial que as mulheres possuem para estarem nestas áreas e exercerem com sucesso e desempenho estes trabalhos aos quais elas associaram inicialmente ao universo masculino.

Pontua-se que há um desconhecimento por parte das alunas acerca do nome de cientistas mulheres e o não conhecimento de mulheres que trabalham nas áreas de engenharias; todavia, as estudantes assentiram que na hipótese de conhecerem mulheres atuando nestas áreas, às quais elas não associavam a trabalho de mulher, elas se sentiriam mais seguras para trilharem o mesmo caminho.

Esta constatação nos permite sugerir que a representatividade feminina em determinadas áreas é fator importante para a escolha de outras mulheres por estes mesmos caminhos e percursos de existência.

Observa-se a partir da análise dos pontos de convergência do grupo focal 2 que as alunas associaram espontaneamente as áreas de engenharia como pertencente ao universo de profissões masculina e o de professora, enfermagem e ginecologista como ao universo feminino, estando estas últimas profissões associadas a características atribuídas à mulher e à questão do cuidado. Nenhuma delas lembrava ou sabia o nome de uma cientista brasileira e todas concordaram que a pouca representatividade das mulheres nas exatas e tecnologias se dava por razões impostas pela sociedade.

Nos chama a atenção o fato de que em nenhum dos grupos focais as estudantes sabiam ou conheciam o nome de alguma cientista brasileira, tampouco uma cientista mulher, de importante atuação. Esse dado revela a pouca representatividade que a mulher possui nas ciências, do ponto de vista da divulgação de seus trabalhos ou mesmo na matriz curricular das disciplinas ofertadas no ensino básico. Nota-se também que as participantes de ambos os grupos focais associaram rapidamente as áreas das engenharias como sendo cursos mais voltados para o universo masculino, embora considerem que as mulheres possuem as mesmas aptidões para o aprendizado e sucesso na conclusão destes cursos.

Estas duas impressões gerais compartilhadas no universo de percepções de ambos os grupos focais confirmam as informações levantadas na recente pesquisa do Instituto Nacional de Ciência e Tecnologia em Comunicação Pública da Ciência e Tecnologia (INCT-CPCT) intitulada "O que os jovens brasileiros pensam da ciência e da tecnologia?" (INCT-CPCT, 2019). Dentre os principais resultados da pesquisa constatou-se que a maioria dos jovens brasileiros manifesta grande interesse por temas relacionados à ciência e tecnologia, percebem a importância social e para o desenvolvimento do país, porém, a maioria das pessoas entrevistas, semelhantes aos resultados encontrados nas discussões do grupo focal, não consegue mencionar o nome de uma instituição brasileira sequer que faça pesquisa, nem de algum cientista ou cientista brasileira.

Mesmo em se tratando de pessoas que vivem em distintos ambientes socioeducacionais, e com distintas condições de vida, as percepções da questão da mulher nas ciências exatas e tecnologias apresenta diversos pontos de convergência e similaridade nas diversas falas das estudantes de ambas as escolas, conforme demonstrado nas tabelas de questões consensuais;

Outro fato notório observado em ambos os grupos focais foi a associação das profissões de professora e enfermeira como sendo as mais indicadas para as mulheres; esta associação, conforme discorrido por elas mesmas no decorrer das discussões, estaria 
relacionada ao fato destas profissões exigirem características pessoais dos indivíduos tais quais delicadeza, paciência, afetividade que estão estritamente relacionadas às mulheres. Estas percepções corroboram com o pensamento de Nicholson (2000) ao ponderar que as concepções biológicas atribuídas ao sexo biológico serviriam de base para as atribuições sociais dos gêneros e também para o fenômeno identificado pela autora como 'portacasaco de identidades', segundo o qual as diferenças biológicas entre homens e mulheres determinariam também diferenças de personalidade e de comportamentos, refletindo desta forma na forma como determinadas profissões ou áreas de atuação são escolhidas por ambos os sexos.

Para a análise reflexiva das questões subjetivas e demais pontos que surgiram nas discussões, igualmente pertinentes para a análise do fenômeno das mulheres nas ciências exatas e tecnologias, foram definidos, por sua vez, a partir da codificação dos sentidos (captação dos conteúdos manifestos e latentes, inferência e interpretação) três categorias de análise para a interpretação das narrativas, conforme apresentadas na tabela 3 .

Tabela 3: Categorias de análises para as narrativas intersubjetivas dos grupos focais 1 (escola pública) e 2 (escola privada).

\begin{tabular}{llll}
\hline \multicolumn{3}{c}{ Categorias de análise } & \multicolumn{2}{c}{ Conceitos norteadores } \\
\hline $\begin{array}{l}\text { Relação sexo biológico versus escolha da } \\
\text { profissão }\end{array}$ & $\begin{array}{l}\text { Esta categoria aborda as opiniões e narrativas das } \\
\text { entrevistadas onde predominam percepções de que a } \\
\text { escolha do curso/profissão se dá em função de } \\
\text { características biológicas e/ou resultantes dos estereótipos } \\
\text { associados ao gênero do indivíduo (BOLZANI, 2017; } \\
\text { D’AMORIM, 1997; NICHOLSON, 2000); }\end{array}$ \\
Escolha da profissão por determinantes sociais & $\begin{array}{l}\text { Ilustra as narrativas das participantes que apontam ser a } \\
\text { escolha da profissão moldada por expectativas e/ou } \\
\text { exigências do meio social (BANDEIRA. 2008; }\end{array}$ \\
$\begin{array}{l}\text { NICHOLSON, 2000). } \\
\text { Papel da educação no processo de emancipação } \\
\text { feminina }\end{array}$ & $\begin{array}{l}\text { Aborda as falas das participantes dos grupos que apontaram } \\
\text { o papel da escola como promotor de emancipação e } \\
\text { empoderamento feminino. }\end{array}$ \\
\hline
\end{tabular}

Fonte: Elaborado pelo autor a partir dos dados da pesquisa (2019).

$\mathrm{Na}$ categoria "relação sexo biológico versus escolha da profissão" observa-se sobre a escolha da profissão e/ou do curso a qual as mulheres seguem balizados por características biológicas ou por características natas pautou-se no ponto de vista de Bolzani (2017), onde destaca que as próprias mulheres, muitas vezes incorporam a visão de mundo na qual a ideia de ser mulher deve está associada a papéis mais voltados para o cuidado, para o afeto, delicadeza etc., e as meninas são naturalmente direcionadas às carreiras das áreas de humanidades e saúde, por exemplo. Dentro desta categoria observouse em ambos os grupos focais a presença de narrativas que convergem com esta perspectiva.

No fluxo de discussão do grupo focal 1 (escola pública) obtiveram-se os seguintes depoimentos que corroboram com esta perspectiva:

"Eu acredito que existem profissões que não são exclusivamente de homens e mulheres, eu acredito que são direcionadas mais para homens, tipo as mulheres são direcionadas mais para o instinto materno algo do tipo, 
então o professor na hora de ensinar, acho que é melhor pra mulher, e homem não tem muita paciência pra isso! (...) eu acho melhor a mulher trabalhar nessa área, até porque a mulher sempre leva pro lado da emoção!" (Aluna da escola pública).

"Enfermagem realmente tem muitas mulheres e poucos homens; Por que é instinto materno também, dessa área, eu acredito que é isso!" (Aluna da escola pública).

"Mulher em si é um pouco mais detalhista do que o homem, eu penso, gosta de está vendo coisinhas aqui ou ali, eu penso, né?!" (Aluna da escola pública).

Percebe-se, dentro da perspectiva destas duas participantes, o quanto aspectos cognitivos e emocionais direcionam-se naturalmente à figura da mulher e estes as direcionam espontaneamente para a escolha de profissões onde tais atributos são valorizados e exigidos socialmente.

Nas discussões do grupo focal 2 (escola privada) igualmente surgiram opiniões que expuseram percepções de que as profissões são escolhidas via de regra a partir de características biológicas e comportamentos tidos como pertencentes naturalmente a um e outro sexo biológico:

"Acredito que não necessariamente um curso, mas profissão; de babá, por exemplo, a profissão que uma mulher exerce de cuidar de uma criança que não seja dela, no padrão da sociedade de hoje em dia é mais comum a gente ver mulher cuidando porque tem aquele dom assim de mãe; por ser mulher, mãe e é até estranho a gente ver um homem cuidando de um bebezinho hoje em dia, mas acho que é mesmo pelo padrão imposto pela sociedade por esse motivo de mulher ser mãe então é mais fácil para ela." (Aluna da escola privada).

"Eu acho que tem profissão que pode ser feita tanto por mulher quanto por homem, acho que não é tanto um padrão imposto pela sociedade, mas acho que é até mesmo um padrão biológico, sabe, pela mulher ser mais carinhosa e não que não exista homem que não possa fazer essas coisas, mas eu acho que pode ser alguma coisa de influência também!" (Aluna da escola privada).

No horizonte de percepções destas jovens mulheres do grupo focal 2 as mulheres possuem naturalmente atributos associados à delicadeza, paciência e cuidado que são características exigidas por profissionais da área de saúde e da educação, o que contribuiria para o maior número de mulheres atuando nestas áreas.

Chama atenção a defesa pontual, presente na narrativa de participantes de ambos os grupos, para a presença do instinto materno naturalmente existente nas mulheres. A este respeito Badinter (1985) teoriza radicalmente que $o$ instinto feminino para a maternidade, bem como o amor materno, assim como quaisquer outros sentimentos, é passível de sofrer transformações, sendo mais ou menos valorizado conforme o contexto social, podendo receber influencias das mudanças que ocorrem nos costumes e aspectos sociais, políticos, econômicos, científicos e filosóficos de determinada sociedade; podendo, inclusive, serem até negados.

Deste modo a autora desconstrói a naturalização compulsória que existe no discurso de que toda e qualquer mulher nasce para ser mãe, o que se contrapõe à defesa das participantes deste estudo que associam naturalmente determinados comportamentos e sentimentos à maternidade.

Com relação à categoria "escolha da profissão por determinantes sociais" quando questionadas: "Porque será que as mulheres vão menos para estas áreas de profissão (exatas e tecnologias)?", pontos divergentes novamente surgiram e várias narrativas eclodiram, demonstrando pontos de vistas que convergem para o fato de que as mulheres são naturalmente condicionadas a ocuparem determinados espaços e posições na sociedade. 
Nas seguintes falas das alunas do grupo focal 1 (escola pública) é possível verificar estas percepções de modo pontual:

"Eu acredito que é da criação ou da oportunidade; por exemplo, meu pai não deixaria eu sair ou ir a uma locadora $e$ passar horas jogando ou ir pra rua jogar bola; depende muito mais da onde a mulher é limitada; principalmente pela sociedade que oprime muito a mulher em muitas coisas e por conta disso a mulher acha que aquilo é pra ela e ela vai fazer aquilo."

"Existe essa questão de desigualdade de gênero que influencia bastante, porque querendo ou não o homem sempre vai ter mais oportunidade; o homem sempre vai ser mais reconhecido do que uma mulher; para uma mulher ser reconhecida por algo ela tem que ser além do que o homem já fez para ela poder ganhar destaque em alguma coisa; então pela falta de oportunidade e pela sociedade ser muito preconceituosa. Porque querendo ou não se ver uma mulher lá na frente, mexendo, por exemplo, com computação vão falar que com certeza ela vai fazer alguma coisa errada! 'Se fosse um homem ali tinha saido melhor!"

"Essa ideia de colocar a mulher sempre em um patamar abaixo do homem! Você fica assim: 'o que que uma mulher vai saber de construção?', 'o que que ela vai saber construir? Daqui a pouco cai, não funciona!'.

"Por muito tempo as mulheres foram limitadas, então hoje, antes da gente escolher alguma coisa vem todas as coisas negativas primeiro e acho que isso influencia muito".

"É o preconceito! Porque querendo ou não isso vem muitas vezes da casa da gente, quando a gente fala uma coisa aí já dizem: 'isso não é para tu não, isso é para teu irmão, isso é pro jeito do teu primo' e a gente mesmo tem esse preconceito quanto a isso e não se permite fazer!"

"Por exemplo, com esse negócio de me alistar, todo mundo na minha casa é militar, então para mim é normal, mas para as outras pessoas que eu contei isso ficaram surpresos com isso: 'Você vai desistir na hora'; Dizem que não vou aguentar a pressão, que não vou dar conta, que vou voltar pra casa na hora!"

Nota-se, portanto, a partir da análise destas falas, o quanto as percepções destas jovens mulheres encontram-se arraigadas por julgamentos e percepções a partir dos quais as mulheres ocupariam determinados espaços e lugares de existência e atuação impostos arbitrariamente pela sociedade. Ainda no grupo focal 1 (escola pública), destacou-se neste sentido, a fala de uma das participantes que ao serem convidadas pelo pesquisador a pensar na seguinte proposta " No caso $d a$ menina que gosta de matemática, de física, por exemplo, vocês acreditam que ela pensa em fazer um curso das áreas de engenharia mais aí ela desiste porque todo mundo diz que aquilo não é para ela?" fez a seguinte colocação:

\begin{abstract}
"Eu até penso que ela poderia fazer engenharia, mas ela teria que está provando o tempo inteiro que ela sabe a respeito. Se um homem falar que é bom em matemática, ótimo, se for uma menina falando que é boa em matemática a pessoa já começa a perguntar quanto é isso vezes isso, já começa a te testar dali, então é uma coisa que você sempre tem que está sendo melhor do que as outras pessoas. E às vezes é cansativo você ter que ficar provando o quanto você é boa e acaba desistindo".
\end{abstract}

Estes depoimentos fazem referência implícita ao processo de segregação vertical teorizado por Olinto (2011), segundo os quais às mulheres estariam sempre destinadas as posições de menor prestígio e reconhecimento social; deste modo, o próprio meio através de mecanismos sutis as direcionariam para estes locais de invisibilidade.

Estes estereótipos de gênero, reforçados nas falas das participantes do grupo focal, são o conjunto de comportamentos socialmente estipulados como sendo próprios para cada gênero e o conjunto de qualidades físicas e características psicológicas associadas a cada um deles. Eles estabelecem 
claramente uma dicotomia entre o feminino e o masculino e estão, segundo Olinto (2011) na base das desigualdades entre homens e mulheres em diversos segmentos e situações, inclusive na escolha e indicação das profissões a serem seguidas por ambos os sexos.

Destarte, outro ponto colocado por uma participante da escola pública e uma participante da escola privada ao serem estimuladas a discorrerem sobre profissões onde predominam a presença feminina, diz respeito diretamente ao posicionamento de Bandeira (2008), quando teoriza que as mulheres estão sujeitas a ocuparem lugares de menor valor social e de menor prestígio em relação aos homens e que estes fatos empurram as mulheres em determinadas direções e as inibem de percorrer outros caminhos em outras situações:

"[...] e vendedora, todo mundo pensa nisso: mulher: vendedora, balconista, caixa de supermercado, recepcionista; são profissões que a gente olha e já vê que é mulher. E são coisas baixas, vendedora, recepcionista, faxineira; é difícil você ver um homem cozinheiro, você não anda vendo faxineiro, cozinheiro; aqui na escola não tem”. (Aluna da escola pública).

"Acho que nem todo mundo corre atrás de uma mulher para colocar num posto tão grande e talvez seja isso. Acho também que duvidam da capacidade da mulher; $E$ sempre vão dar preferência para os homens e não para a mulher." (Aluna da escola privada).

Esta última fala presente quando foram convidadas a pensar de modo mais reflexivo sobre a pouca presença das mulheres nas áreas de exatas e tecnologias, aponta para o fato de que a mulher estaria sempre sendo colocada em situação de desvantagem em relação ao homem quando atuando nestas áreas, e, portanto, para evitar o desgaste já se inibiria a percorrer este trajeto acadêmico e profissional.
A influência da sociedade e a formação cultural e familiar fora outro ponto igualmente apontado em ambos os grupos focais como sendo os responsáveis pelas escolhas das profissões pelas mulheres; a este respeito, destaca-se a fala de uma integrante do grupo focal 1 (escola pública) e de outra integrante do grupo focal 2 (escola privada) que apontaram para este processo:

"[...] Porque querendo ou não isso vem muitas vezes da casa da gente, quando a gente fala uma coisa aí já dizem: isso não é para tu não, isso é para teu irmão, isso é pro jeito do teu primo e a gente mesmo tem esse preconceito quanto a isso e não se permite fazer." (Aluna da escola pública).

"[...] Eu acho que é uma coisa desde criança sabe? Quando você é menina você ganha uma boneca es meninos um carrinho, um vídeo game. As meninas sempre ganham coisas de boneca de médico, essas coisas assim mais ligadas a casa, cuidado mesmo." (Aluna da escola privada).

Confirma-se deste modo, a partir destas falas, o que fora pontuado por Shumaher (2004) e Ribeiro (2006) ao pontuarem que meninos e meninas são desde muito cedo educados para ocuparem determinados papéis sociais em decorrência do sexo biológico.

Por fim, na categoria "papel da educação no processo de emancipação da mulher”, em ambas as escolas as meninas colocaram sobre a importância da educação no processo de emancipação da mulher no sentido de instruírem-nas quanto aos rumos de suas escolhas. Esta indagação corrobora com o pensamento de Bolzani (2017) ao ponderar que a mudança desse quadro de desigualdade comporta algumas medidas básicas, que devem começar no ensino fundamental. Para a autora a escola precisa despertar na criança, independente do gênero, a curiosidade e a consciência de que conhecer o universo é uma atividade que a torna mais rica como ser humano. 
"Eu acho que seria bom a escola tentar promover essa ideia de mulher poder tá onde ela quer, sabe? porque a gente precisa dessa atenção! por que se tiver só a gente pensando a gente diz: não eu não posso fazer isso! Se tiver alguém do nosso lado que já fez aí facilita muitas coisas ou então se a escola determinasse certas profissões". (Aluna da escola pública)

"Acho que a escola deveria fazer mais debates e palestras sobre isso!" (Aluna da escola privada)

"Na verdade eu nunca tinha parado pra pensar nisso! Tem que ter mais discussão sobre isso na escola!" (Aluna da escola privada)

"Acho que tem que ser colocado isso homens e mulheres em todas as áreas- de forma natural por que não precisa ser um movimento grande, mas algo natural, tanto em casa na hora de educar os filhos, tanto na escola". (Aluna da escola privada)

Estas falas guardam semelhança com as palavras de Bian et al. (2017), onde afirmam que família e escola são cúmplices em ensinar que destreza com ferramentas e foco são atributos masculinos, enquanto sensibilidade, cuidado e cooperação são qualidades femininas. Nas palavras dos autores, estereótipos comuns associam capacidade intelectual de alto nível (brilho, genialidade, etc.) a homens mais do que a mulheres e esses estereótipos desencorajam a busca de muitas carreiras de prestígio por parte das mulheres.

Apesar do imaginário destas jovens mulheres estarem povoado por um conjunto de ideias e percepções que ainda veem a mulher como passiva a um conjunto de normativas e condutas impostas pela sociedade, em ambos os grupos focais surgiram narrativas que demonstram o conhecimento, por parte das participantes, de um movimento recente que tem conduzido a sociedade a um patamar de equidade de gênero e que vem dando voz e vez às mulheres:
"Eu acho que a gente precisa de mulher mais ousada, daquelas que batem no peito e dizem: eu vou! Acho que precisamos ser mais corajosa porque a gente é muito na nossa!"(aluna da escola pública).

"[...] a mulher agora tem mais voz! Se eu quisesse fazer um curso destas áreas acho que eu não teria mais medo; antigamente talvez sim. Se eu tivesse esse dom eu faria sem medo, eu iria provar para todo mundo que nós somos capazes!" (aluna da escola privada).

"Na minha casa mesmo não tem essa coisa de mulher fazer isso ou aquilo. Isso era muito de antigamente, mas agora está melhorando, mas antes era assim; Acho que hoje está mudando muito, tem mulher em tudo, mas ainda tem isso!" (aluna da escola privada).

Assim sendo, pontua-se que embora haja algumas contradições presentes nas narrativas destas jovens mulheres, de ambos os grupos focais, novos horizontes de existência e de atuação se descortinam no porvir: horizontes estes de esperança e igualdade, independente do gênero ou condição social.

Do mesmo modo que no estudo de Costa e Fernandes (2017), onde mesmo sendo relativamente baixo o número de associações de mulheres como sendo cientistas, a simples presença dessa representação anuncia uma transformação no estereótipo, que já prevê outra figura além da masculina preconizada pela cultura hegemônica. As autoras finalizam o estudo defendendo que é necessário que a educação básica se aproprie do movimento emancipatório da mulher na ciência e expor mais exemplos de mulheres cientistas no currículo, tornando a ciência menos masculina e mais igualitária, para que mais meninas possam, a exemplo das participantes desta pesquisa, enxergar seu futuro como cientistas.

\section{CONCLUSÃO}

Este estudo foi motivado primordialmente pela constatada disparidade de gênero existente em 
determinadas áreas e espaços da sociedade, estando a mulher em condição de desigualdades em relação aos homens. Pretendeu analisar como adolescentes concluintes do ensino médio de duas escolas localizadas em distintos ambientes socioeducacionais concebem acerca da inserção e atuação das mulheres nas ciências exatas e tecnologias.

Foi possível observar, com relação às análises decorrentes da realização dos grupos focais, que independente de contexto social, econômico e escolar muitos estereótipos de gênero estão presentes no horizonte de percepções e ideias destas jovens mulheres, e deste modo, a ainda pouca representatividade feminina em áreas culturalmente e historicamente dominadas pela presença masculina pode ser decorrente das representações que as próprias mulheres possuem de si mesmas e do mundo que as cerca.

Compreender o modo como estas jovens mulheres percebem a atuação e inserção de seus pares no universo das ciências e tecnologias é indispensável para se pensar em políticas públicas, ações e projetos que contemplem esta demanda. Mesmo sendo este estudo composto por uma pequena amostra que não representa a visão global da temática foi possível verificar a presença de narrativas arraigadas por uma visão ainda marcadamente engendrada no que se refere à presença e atuação das mulheres nas áreas de exatas e tecnologias.

Aqui, finalizamos apenas este estudo, não pretendemos de modo algum esgotar o assunto, tampouco estabelecer afirmações absolutas ou imutáveis no tempo, pelo contrário, intencionamos provocar novos questionamentos e discussões a partir da visibilidade dos fatos e das percepções aqui apresentadas. Sugerimos que futuros estudos acerca das questões de gênero sejam igualmente empreitados com olhares voltados para este e outros vieses, tendo sempre como plano de fundo a perspectiva da equidade de gênero, da igualdade de oportunidades e da justiça social.

Todos os autores declararam não haver qualquer potencial conflito de interesses referente a este artigo.

\section{REFERÊNCIAS}

BADINTER, Elisabeth. Um amor conquistado: o mito do amor materno. Tradução de Waltensir Dutra. Rio de Janeiro: Nova Fronteira, 1985.

BANDEIRA, Lourdes Maria. A contribuição da crítica feminista à ciência. Revista Estudos Feministas. Vol. $16,2008$.

BARBOUR, Rosaline. Grupos focais. Porto Alegre: Artmed, 2009.

BARDIN, L. Análise de conteúdo. São Paulo: Edições $70,2011$.

BIAN, Lin; LESLIE, Sarah-Jane; CIMPIAN, Andrei. Gender stereotypes about intellectual ability emerge early and influence children ${ }^{e e}$ interests. Science. Vol. $355,2017$.

BOLZANI, Vanderlan da Silva. Mulheres na ciência: por que ainda somos tão poucas? Ciência e Cultura. [online]. Vol. 69, 2017.

BRASIL. Constituição da República Federativa do Brasil: D.O. U. 5 de Outubro de 1988.

CARVAlHO, Maria Eulina Pessoa de Carvalho. Pierre Bourdieu sobre gênero e educação. Revista Ártemis. Vol. 1, 2004.

O conceito de gênero: uma leitura com base nos trabalhos do GT Sociologia da Educação da ANPED (1999-2009). Revista Brasileira de Educação. Vol. 16, 2011. 
COSTA, Angelica Felício; FERNANDES, Hylio Laganá. Mulher na ciência: concepções de estudantes na fase da adolescência. Enseñanza de las ciências. Vol. 35, 2017.

D' AMORIM, Maria Alice. Estereótipos de gênero em universitários. Psicologia - Teoria e Crítica. Vol. 1, 1985.

Estereótipos de gênero e atitudes acerca da sexualidade em estudos sobre jovens brasileiros. Temas em psicologia [online]. Vol. 1, 1997.

ELSEVIER. Gender in the Global Research Landscape. 2017. Disponível em: https://www.elsevier.com/researchintelligence/campaigns/gender-17 . Acesso em: 22 jan. 2019.

IBGE. Síntese de indicadores sociais: uma análise das condições de vida da população brasileira. Rio de Janeiro. IBGE. 2019.

INCT-CPCT. Instituto Nacional de Ciência e Tecnologia em Comunicação Pública da Ciência e Tecnologia. O que os jovens brasileiros pensam da ciência e da tecnologia? Resumo Executivo. Fundação Oswaldo Cruz: Rio de Janeiro, 2019.

LETA, Jacqueline. As mulheres na ciência brasileira: crescimento, contrastes e um perfil de sucesso. Revista Estudos Avançados. Vol. 17, 2003.
MATOS, Maria Izilda Santos de. Da invisibilidade ao gênero: percursos e possibilidades nas Ciências Sociais contemporâneas. Revista Margem. Vol. 1, 2002.

NICHOLSON, Linda. Interpretando o gênero. Revista Estudos Feministas. Vol. 8, 2000.

OKA, Mateus; LAURENTI, Carolina. Entre sexo e gênero: um estudo bibliográfico-exploratório das ciências da saúde. Saúde e Sociedade (Online). Vol. $1,2018$.

OLINTO, Gilda. A inclusão das mulheres nas carreiras de ciência e tecnologia no Brasil. Revista Inclusão Social. Vol. 5, 2011.

RIBEIRO, Jucélia Santos Bispo. Brincadeiras de meninas e de meninos: socialização, sexualidade e gênero entre crianças e a construção social das diferenças. Cadernos Pagu. Vol. 1, 2006.

SCOTT, Joan. Gender: a useful category of historical analyses. Gender and the politics of history. New York: Columbia University Press. 1989.

SHUMAHER, Schuma. Uma escola que educa cidadãs e cidadãos. In: GONÇALVES, Eliane. (org.). Desigualdades de gênero no Brasil: reflexões e experiências. Goiânia: Grupo Transas do Corpo, 2004. 